\title{
El (proto) nacionalismo de Maquiavelo y Rousseau y sus repercusiones en la política*
}

Recibido: noviembre 2 de 2015 | Aprobado: 11 de abril de 2016

DOI: 10.17230/co-herencia.13.24.3

\section{Antonio Hermosa Andújar**}

hermosa@us.es

\begin{abstract}
Resumen
En el presente trabajo nos proponemos examinar el papel desempeñado por las ideas que acerca del nacionalismo es posible rastrear en las doctrinas políticas de Maquiavelo y Rousseau, incluyendo su repercusión sobre el orden establecido con anterioridad a su elaboración. Como tales repercusiones afectan negativamente a las respectivas teorías de la política y la democracia, llevaremos a cabo también un breve análisis acerca de si el mal aportado en ambas concepciones constituye asimismo un destino prescrito para el nacionalismo.
\end{abstract}

\section{Palabras clave:}

Maquiavelo, El príncipe, Rousseau, El contrato social, nacionalismo.

\section{(Proto)nationalism of Machiavelli and Rousseau and its political repercussions}

\begin{abstract}
In this article we aim to address the role played by nationalism tracing it back to the political doctrines of Machiavelli and Rousseau. This includes its repercussion on the order established previous to its drafting. As such repercussions adversely affect the respective ideas of democracy and theories of politics we will also carry out a brief analysis on whether the idea of evil provided in both conceptions does indeed represent a prescribed destiny to nationalism.
\end{abstract}

\section{Key words:}

Machiavelli, The Prince, Rousseau, The social contract, nationalism.
* Este artículo presenta un resultado del trabajo desarrollado dentro del Grupo de Investigación HUM-153. Filosofía de la Cultura, Universidad de Sevilla-España.

** Doctor en Filosofía, UNED - España. Profesor, Universidad de Sevilla - España. Director de Araucaria. Revista Iberoamericana de Filosofía, Política y Humanidades. 


\section{El nacionalismo en Maquiavelo}

En el último capítulo de El Príncipe hay de repente un cambio de escenario: Italia ocupa ahora el lugar prioritariamente poblado por las ciudades-Estado en el contexto anterior. Ello no parece afectar, en principio, al problema planteado por Maquiavelo, a saber: ies posible recrear actualmente Italia? Vale decir: ¿es posible unificarla y devolverle su perdida grandeza? Y no parece afectarlo porque la solución, en apariencia, es la misma que en otros casos precedentes, la de seguir "las acciones y vida" de los grandes prohombres del pasado, como Ciro, Rómulo o Teseo, capaces con sus gestas de emular las del mismísimo Moisés, es decir, indirectamente las del propio Dios. Italia, en efecto, se halla en una situación límite, de hecho más grave que cualquiera de las mencionadas en el capítulo VI: "más esclava que los judíos, más sierva que los persas, más dispersa que los atenienses”, en la más completa anarquía y ruina. Más necesitada por tanto del héroe que la recomponga, ese príncipe "prudente y virtuoso" cuya acción media entre la "materia" y su futura "forma" - la elegida por él entre las diversas posibles- una vez individuada en las condiciones actuales la "ocasión" de hacerlo. ${ }^{1}$

$\mathrm{Y}$, sin embargo, pronto entran en escena personajes antes desconocidos: es "Dios" mismo quien pareciera haber elegido a algún personaje que luego se ha revelado poseído por el demonio de la fortuna, mas el momento ha llegado de que su dedo toque al ungido y se lleve a término la obra de "redención" que la grey italiana ansía en lo más íntimo de su corazón. Una legitimidad carismática y teológica le lloverá así del cielo al príncipe antaño reducido a su sola virtù a la hora de conquistar y legitimar su trono. Por otra parte, la grey itálica ya ha puesto todo de su parte al servicio del mentado ideal; a falta de cabeza que le guíe, el cuerpo "virtuoso" dispuesto a dejarse guiar, y a dejar la vida en la empresa, palpita febrilmente a la espera de la hora redentora: Maquiavelo ni sabe "expresar con qué amor sería recibido en todas aquellas tierras que han padecido estos aluviones extranjeros; con qué sed de venganza, con qué obs-

\footnotetext{
Materia, forma, occasione, virtù: conceptos todos ellos presentes ya en el citado capítulo VI, y que parecen confirmar la validez de la teoría aun cuando la acción principesca apunte al entero país en lugar de a una cualquiera de sus ciudades o potencias (Venecia, por ejemplo). Las citas provienen de mi propia edición de El Príncipe (2006), y salvo indicación expresa todas ellas se encuentran en el cap. XXVI, el último. Véase asimismo la segunda introducción presente en la edición citada: "De Florencia a Italia: Maquiavelo, nacionalista".
} 
tinada lealtad, con qué devoción, con qué lágrimas. ¿Qué puertas se le cerrarían? ¿Qué pueblos le negarían obediencia? ¿Qué envidia se le opondría? ¿Qué italiano le negaría su reconocimiento? A todos repugna este bárbaro dominio" (2006: 150). Añádase a todo ello la presencia de la "Iglesia", máxime ahora que el futuro príncipe es amo suyo vía familiar, la cual lo nombraría su favorito. Dios, una nación en armas ${ }^{2}$ y la Iglesia, la santa trinidad escatológica antaño ignara a la arena política y puesta por la ideología nacionalista al servicio del también nuevo señor. ${ }^{3}$

Por lo demás, recrear Italia no es solo unificarla, sino mantenerla tal; no se trata únicamente de dar vida a la antigua patria, sino de preservarla. Ello abarca por tanto el entero proceso del mecanismo político: el acceso al Estado y su conservación. La trinidad aliada del príncipe le ha facilitado sobremanera desarrollar con éxito la primera fase. La justicia de la causa no conoce parangón actual; y la "disposición" del pueblo, presto "a seguir una bandera", es total y absoluta: "y no puede haber gran dificultad donde la disposición es grande" si el príncipe sigue los modelos históricamente testados. Repetir ese éxito en la segunda fase le exigirá refundar el viejo orden, vale decir, establecer una nueva constitución en la que las leyes promulgadas y las instituciones creadas lleven indeleblemente su impronta, cosa nada difícil, prosigue Maquiavelo, habida cuenta de que la virtù itálica permanece como dato probado en el corazón de los italianos. El honor que le espera es la veneración de su pueblo y el reconocimiento de los demás, la máxima gloria al alcance de un ser humano en el mundo.

Hasta aquí el apretado esquema del balance de las ideas nacionalistas en el segretario fiorentino que deshace de inmediato la señalada apariencia del funcionamiento de la misma medicina si es aplicada por un príncipe nuevo a la Florencia de turno o por un príncipe antiguo a una Italia renovada. Si bien Maquiavelo insiste en la perenne validez de los modelos a imitar o en la urgencia de formar "un ejército propio" como medida primera para ese fin, lo cierto es

El lector (máxime si es francés) sabrá disculpar la licencia de aludir libremente al célebre verso de La Marsellesa. Sobre el himno francés puede verse el maravilloso escrito de Stefan Zweig (2002: 121-137).

Aunque no se pretenda, la concentración axiológica del valor en torno a la Patria automáticamente deja en estado de naturaleza moral al resto del mundo. Por eso será consecuente Maquiavelo cuando en el célebre cap. 41 de los Discursos sobre la primera década de Tito Livio (1987: Libro III: 410-411) afirme que cualquier procedimiento es válido (sea "piadoso o cruel, justo o injusto, laudable o vergonzoso") con tal de preservar su seguridad y libertad (Gerhard, 1972: 47). 
que mucho ha cambiado en el contexto político como para aceptar sin más el diagnóstico o la prescripción. Y ello tanto en lo que hace a la "cabeza" como respecto del "cuerpo" dos partes ahora de un mismo individuo que antes en absoluto lo era. El nacionalismo ha hecho brotar en la escena política a tres nuevos actores que más que enriquecerla la empobrecen: Dios, el Pueblo (armado) y la Iglesia, y con ellos un andamiaje de trascendencia que corona incluso la próxima acción del ejército, las bendecidas pia arma tomadas de la pluma de Tito Livio, que reconquistarán, en combate contra el "bárbaro", la perdida unidad de Italia. El bárbaro es en este punto el extranjero que la oprime, ${ }^{4}$ de la nacionalidad que fuere, comprendidas aquellas que tanto tenían que enseñar antaño en materia de unidad estatal, como Francia o España, lideradas ocasionalmente por príncipes cuyas acciones habían sido ennoblecidas como exempla por la teoría, como en el caso de Fernando el Católico. Todo ello acarrea, pues, una nueva visión de la realidad histórica y un nuevo esquema valorativo de la misma, pues la Italia enfocada por el análisis se presenta como permanentemente virtuosa, fuerte y civilizada, olvidando así, respectivamente, la queja amarga de haber sido ultrajada por las correrías de Carlos VIII de Francia con la "tiza", los conflictos constantes entre sus diversas partes y sus distintos jefes, que tanto la habían postrado, y los muchos ejemplos a seguir sacados de las filas de los ahora, sin más, "bárbaros".

Las repercusiones sobre el mundo de ideas construido anteriormente no se hacen esperar y es menester señalar desde ya que la política no sale bien parada del choque. Y tanto en lo concerniente al acceso al poder, al trono itálico, cuanto a su conservación. Respecto del acceso, la virtù del príncipe -ese híbrido especial compuesto de cualidades personales y acciones, que capacitaba a su titular para ejercer el mando en un Estado determinado- conocía dos momentos estelares, la individuación de la "ocasión" ${ }^{\text {y }}$ la persuasión para que sus partidarios se mantuviesen como tales en el perentorio momen-

4 Cualquier extranjero de hecho, siempre inferior al italiano en una comparación cuerpo a cuerpo "en fuerza, destreza o ingenio". Adviértase además que entre las pasiones enumeradas se halla "el deseo de venganza”, una de las pasiones típicas de la libertad (Cfr. Cap. V), según hemos expuesto en un texto anterior, que la nación usurpa en este punto, por cuanto la nación, aquí, no es precisamente republicana.

5 Un territorio en principio asignado a la fortuna, pero que el razonamiento maquiaveliano del cap. VI pronto convierte en una provincia de la virtù misma. 
to del cambio, cuando las circunstancias militaban todas en pro del orden antiguo. En el primer caso, el héroe demostraba en el campo militar su talla de futuro estadista al ser capaz de ver sobre la superficie de una historia derrotada, en la que campaban a sus anchas sujetos empobrecidos, humillados y desunidos, el momento justo de poner los cimientos del venidero Estado. Un golpe de audacia moral y política que inventaba desde la nada un proyecto de convivencia capaz de llenar el alma de individuos desalmados con las ilusiones y esperanzas de un pueblo, y que recomponía la perdida continuidad de su articulación histórica.

El segundo caso era infinitamente más trascendente, pues suponía un ajuste de cuentas con la condición humana en persona, al imprimir en ella cualidades que ampliaban sus capacidades de acción; pero lo hacía, nada menos, violando las leyes de su constitución, las que le habían hecho ser como era. En un contexto en el que el aspirante a príncipe se juega su futuro en el campo de batalla, y en el que ha de dar forma a la empresa más difícil que a hombre alguno le quepa ejecutar -la fundación de una nueva institucionalidad-, todo conspira contra él; sus enemigos, en efecto, tienen como aliado la legitimidad del orden antiguo que se aspira a cambiar, fuente de su interés; entre tanto sus partidarios, aparte del miedo a todo eso, padecen también esa desconfianza típica de todo ser humano ante lo nuevo, que solo desaparece cuando deja de serlo: cuando se ha familiarizado con ello y los temores iniciales se han disuelto en el tiempo. La virtù del príncipe alteraba la naturaleza humana porque era capaz de hacer aceptar lo nuevo antes de ser experimentado, lo que lo transformaba en una suerte de deidad sobre la tierra. Con ello suplía la "tibieza" en el combate que movía a quienes lo apoyaban, contrapeso ideal del "espíritu faccioso" que agitaba al bando rival contra él (Maquiavelo, 2006: 75).

Ambas apoteosis de la virtù se han esfumado con la entrada en liza del nacionalismo en la vida de la nación. Quien atisba y desea la ocasión no es precisamente el príncipe, sino uno de sus súbditos, quien aspira a legarle el deseo con sus ideas (además de otros beneficios personales por completo comprensibles, dada su situación personal). Y a la persuasión no es menester recurrir ante un pueblo autoconvencido, por lo cual semejante privación de su ejercicio debilita no solo a la política, simplificada en su ser, sino a la mismísi- 
ma naturaleza humana, privada así de la posibilidad de expandirse. Tampoco la formación del ejército propio ${ }^{6}$ será otro lugar para el ejercicio de la virtù, y por la razón recién señalada: el pueblo convencido de serlo es un pueblo ya armado y deseoso de poner en práctica su convencimiento, el hecho de ser uno.

En lo concerniente a la conservación de un trono obtenido, se diría, mediante la virtud afortunada del nacionalismo, las peripecias devienen análogas a las del caso anterior, y el resultado, idéntico. El príncipe italiano, si accede al trono por su virtù, la probará tan solo frente a las potencias extranjeras a las que habrá de arrebatar el claro objeto de sus deseos (el resto, según acabamos de ver, está ya hecho, siendo el artífice el sentimiento nacional). Menos aún se hallará en la situación del príncipe que se ve en el trono al abrir los ojos tras un sueño, en cuanto beneficiario de la fortuna, y que, por norma general, ni sabe ni puede gobernar, puesto que procede del ámbito civil y, por tanto, los conocimientos requeridos para lo primero o las armas exigibles para lo segundo no están al alcance de su mano: y, por ello, se hundirá. Salvo si posee una virtù sobrenatural, que al príncipe italiano, en todo caso, no se le exige ni necesita. Lógicamente, su consecuencia virtuosa inmediata no se dará; el Estado, como todo ente natural, necesita de raíces para echar frutos -condensados en la adhesión de sus ciudadanos-, y de tiempo para echar raíces. La excepcional virtù del nuevo héroe estatal mantenía en cambio la naturalidad del objeto prescindiendo de su condición, el tiempo. Devenía en tal modo una especie de artificio que, sin dejar de ser naturaleza, merced a la potencia señalada obtenía los efectos sin pasar enteramente por la causa y sobreviviendo de manera vital a la muerte que debe acompañar a semejante ausencia. Lejos de todo eso, el príncipe italiano sabía porque provenía de una dinastía de príncipes y podía porque poseía un ejército preconstituido de italianos dispuestos a dar su vida por defenderlo si él defendía a su patria.

Las demás gestas de la virtù correrán idéntica suerte. Si ser y sentirse italianos transforma en secundarias las secuelas de la antevista radical división social de clases, a la que acompañaba la escisión de la esfera moral y probablemente la de las respectivas cosmovisiones; si ahora la emoción de saberse connacionales restaña las heridas

\footnotetext{
Maquiavelo cambia el contexto de dicho ejercicio de virtù, pues el futuro monarca italiano debe hacerse con un ejército de ciudadanos para conquistar Italia antes de conservarla, que era cuando César Borgia debía hacerlo si quería preservar su trono en la Romaña.
} 
que el estatus, el pedigrí o la ambición, y su cortejo de violencias, producían en las relaciones sociales, devolviéndolas a un estado de armonía antaño desconocido u olvidado; si el príncipe, que por ser absoluto está super partes, ha encontrado en la ideología nacional el cordón umbilical que le liga indefectiblemente a su pueblo; si todo eso ocurre: ipara qué requerirá el príncipe una virtù que se ejercitaba cuando, por ocupar la cima del poder, buscaba sobre todo mantenerse a cualquier precio; para qué requerirá matar a los hijos de Bruto, es decir, demostrar prudencia en la administración de la violencia, en la puesta en práctica de las "crueldades bien usadas"; para qué apresurarse en buscar apoyo en el pueblo frente a los grandes, aun si hubiesen sido éstos quienes pusieran el trono a sus pies? Si los intereses del uno frente a los demás, y de los grandes frente al vulgo, ya no laceran la armonía social ni rasgan el velo de la unidad de su destino, ¿para qué necesitará usar instrumentalmente la ética o la religión, enfrentarlas a ambas con la política, manchar las leyes con sangre urgido por la necesidad o la excepción, cuidarse en sus decisiones de no aparecer ante el pueblo odioso o despreciable? Por algo se nos dice ahora, frente al uso de la fuerza esgrimido en el discurso precedente, que la conservación del Estado exige -solo- promulgar nuevas leyes.

La consecuencia de todo ese inesperado curso de ideas es doble. De un lado, se neutraliza notablemente el conflicto, ese manantial de la libertad en Maquiavelo y de la política en general, sin el cual esta no podría ser -ni, siendo, sobrevivir-, y por ende ocupar su lugar específico y realmente imprescindible en la sociedad, en cuanto escenario pluralista en el que innumerables intereses, concepciones del bien y visiones del mundo contienden pacíficamente bajo una ley común que aspira a tolerar su existencia sin confundir sus fines (Crick, 1971: 16-18). La política inicia un movimiento de repliegue que, como en la corte del filósofo-rey platónico, la lleva a desaparecer en el ámbito interno, a la sombra de una ideología que cuenta ahora con el insospechado valor del sentimiento nacional, apoyado por la trascendencia, para calmar los conflictos donde antaño se jugaba la suerte de la sociedad y de sus integrantes. Y habría desaparecido del todo de no ser porque Maquiavelo sigue considerando el ámbito de las relaciones interestatales como un estado de naturaleza, y ahí el príncipe tiene licencia para todo en aras del interés 
nacional, y cumplirá las promesas si quiere, o si no, disimulará sus intenciones en los hechos y esconderá la verdad en sus palabras.

De otro lado, la nueva Italia no será una república, porque no lo necesita. Si los requisitos que autorizan a la política a ser (como es) han desaparecido, si la política misma tiende a ser un vano auxiliar de la ética o la religión gracias a la existencia de una conciencia y un sentimiento nacionales, tampoco se requerirá la compleja institucionalidad republicana -paradójicamente el régimen más natural frente al artificio del principado absoluto- para gobernar un Estado. Una sola persona podrá encarnar el único interés que cuenta, el común, y representar a los demás en el ejercicio del poder. Una nación, con un solo interés, una sola tradición, un solo pasado, una sola cultura, una sola memoria, una sola opinión, cabe entera, por tanto, en la voluntad de uno, que puede querer por todos queriendo en nombre de la voluntad general de la Nación.

\section{El nacionalismo en Rousseau}

En 1771, casi una década después de El contrato social (1762), Rousseau publica las Consideraciones sobre el gobierno de Polonia y su proyecto de reforma, como resultado de sus reflexiones sobre la propuesta del noble polaco Wielhorski de redactar una especie de proyecto constitucional para su país. En teoría, bien podría haberse tratado de una simple ocasión para comprobar cómo los principios políticos teóricos se ajustan a la realidad; en la práctica fue mucho más.

En Du contrat social Rousseau utilizó unos materiales muy livianos en la construcción de la sociedad; le bastó con que un conjunto de individuos libres e iguales se asociara por medio de un pacto mutuo para que de un deseo de su voluntad germinara de manera espontánea el entero edificio del Estado, compuesto de un órgano soberano integrado por todos los pactantes o Voluntad General; ${ }^{7}$ de leyes, que no eran sino otras tantas manifestaciones de su voluntad, y a las que estaban sujetos los demás poderes públicos, así como la totalidad de los súbditos (los integrantes del Estado fuera de él),

\footnotetext{
La Voluntad General, al estar compuesta por todos, no admite la representación; al ser soberana, rechaza la división de poderes; al ser individuos singularmente considerados quienes la integran, se opone a cualquier tipo de asociación o partido que aísle en grupos a los ciudadanos y los enfrente entre sí (Rousseau, 1964: II, 1; II, 2 y II, 6).
} 
pero no el legislativo que las hacía; y, finalmente, del poder que las aplicaba, el ejecutivo (también se alude al poder judicial, si bien de este apenas había noticia en el libro), que podía tener tres formas, monárquica, aristocrática o democrática, aun cuando se prefiriese la segunda, ${ }^{8}$ y siempre dependiente del legislativo soberano. De hecho, éste abría sus asambleas con dos preguntas tópicas de control político, tanto sobre el órgano ejecutivo como sobre quien lo administra: ise mantiene la actual forma de gobierno; se mantiene a quien o quienes desempeñan el cargo?

En el esquema legitimador de ese tronco político, en el que el racionalismo incluía a todos los Estados posibles, Rousseau injertaba una serie de condiciones sociológicas que operaban una fuerte restricción parmenídea en las posibilidades de desarrollo empírico del Estado racional. Así, el arte político debía concentrar ahora sus fuerzas en un pueblo esparcido a lo largo de un territorio no demasiado extenso, no demasiado numeroso, tomado en una fase aún juvenil de su historia, y que en el momento de la refundación gozara de prosperidad y paz. La última de las condiciones garantizaría el éxito de la empresa, en tanto las tres anteriores posibilitarían su intento, básicamente porque la corrupción aún no había tenido tiempo de deteriorar de manera irremisible el carácter ni las costumbres del pueblo. ${ }^{9}$

Ahora bien, cuando Rousseau acepta ordenar Polonia, ni su territorio ni su población son pequeños, ni su historia es joven, y ni siquiera goza de abundancia o paz. Empero, quiere vivir bajo leyes, esto es, ser libre. Eso significa romper moldes, es decir, requisitos, pues se ve así que un pueblo no envejecido por su historia significa una historia no envejecida por la inmoralidad. ${ }^{10} \mathrm{El}$ primer efecto perceptible es, por tanto, que necesariamente Polonia es más que la simple aplicación de los principios de El contrato social a una circunstancia dada. Será mucho más.

8 A no ser que el territorio fuera lo bastante extenso para hacer preferible un gobierno monárquico o bien el pueblo estuviera constituido por ángeles, en cuyo caso la opción sería la democrática (Cfr. el libro III para cuanto concierne al poder ejecutivo).

9 Cabría añadir aquí una quinta condición aun cuando Rousseau no la considere como tal, puesto que la incluye en el cuerpo doctrinal, y es la presencia de un legislador. Condición forzada porque un pueblo inexperto solo sabe que debe tener leyes, mas no qué leyes tener, y esa es la gran obra histórico-jurídica del legislador (Rousseau, 1964: II, 7). Empero, ni Rousseau era sin más un legislador ni a la Polonia de su época le faltaban luces para necesitarlo.

10 Cfr. mi estudio preliminar "El Proyecto y las Consideraciones: evolución e involución en el pensamiento político de Rousseau", en mi edición de los textos de Rousseau sobre corsos y polacos (1988), p. XXVIII. 
Un pueblo real es infinitamente más que un conjunto de individuos libres e iguales, por sabiamente ordenado que esté. Y en ese más caben mil cosas en grado de atentar contra la libertad e igualdad de los individuos, pero eso sucede cuando se entra en un mundo real compuesto por individuos reales. Mil cosas susceptibles de coartar el puro ejercicio de la voluntad, aunque también capaces de movilizarla; de condicionar los problemas, pero también de inventar soluciones; de extender los prejuicios, mas asimismo de contrapesarlos; de confundir a la razón u ofuscar a la imaginación: e igualmente de dilatar su radio de acción e iluminarlas; etcétera. Hay historia, hay tradiciones, hay cultura, hay transformaciones, hay divisiones, hay sensibilidad, hay símbolos, hay ritos; un río de vida fácilmente en conflicto, que no siempre existe -y apenas palpita- en las frías estancias del racionalismo político.

Un pueblo ya unido quiere en esta hora histórica refundarse. No unirse, como en El contrato social, pues lo está, pero sí reunirse de acuerdo con otros patrones jurídico-políticos diferentes de los hasta entonces vigentes. ¿Qué le prescribirá Rousseau? Ante todo, atenerse a una máxima claramente basada en el sentido común, y por ende no necesitada ni del nacionalismo ni del racionalismo para registrarse en la mente de los polacos: si a pesar de las irregularidades constitucionales de la actual norma básica polaca hay Estado y la ciudadanía quiere libertad, tan claro queda que es menester cambiar para corregir los desvaríos normativos, cuanto que los cambios deben respetar el espíritu de lo que ha hecho a los polacos ser como son: libres moralmente en cuanto quieren vivir bajo leyes. ¿Y cuál es el íter marcado por la máxima? Comenzar recabando el refugio de la historia, aunque no de la historia nacional, por sorprendente que en este punto pueda parecer, sino de la historia antigua. Es así como el espíritu de la actual Constitución entronca con el de ciertas constituciones antiguas. ¿En qué consiste?

Por compendiarlo en una fórmula: en singularizar a un pueblo para separarlo de los demás. Lo cual, por cierto, nos hace ver que, ordenándose privadamente cada pueblo según su forma peculiar de ser, el paralelismo entre ambos espíritus, el moderno de Polonia y el antiguo de Esparta - por hacer honor a la cita de Licurgo-, solo puede ser formal. La misma idea moldea a cada pueblo según el material de que se compone, y por tanto modela siempre una escultura histórica claramente diferenciada de sus pares. Y es ahí donde trasparece la 
idea nacional. Y, con ella, el nacionalismo, la ideología que coadyuva imperiosamente a dar forma terrenal a aquélla. Veamos cómo esto, válido por doquier, tiene lugar en Rousseau.

No deja de ser llamativo que también en este punto un contenido nacionalista acabe sedimentándose en la fórmula del ideal político racionalista, la cuadratura del círculo, con el que se construyó el sistema anterior. El círculo político se cuadra allí donde la ley reina en el corazón de los ciudadanos, donde ella se convierte en acicate de su conducta no por necesidad, temor o deber, sino por amor. Cómo anomalía semejante pueda tener su altar en el corazón de un súbdito cualquiera no deja de ser una ilusión en todo tiempo, y un misterio en la sociedad contemporánea. Pero Rousseau labora sin pausa con la mira puesta en su concreción, y en Polonia cree haber dado con la clave que le permite reproducirlo: la clave nacionalista, insistimos, con la cual dar solución a un problema racional. ¿Cómo logrará asentarse la ley en el corazón de los ciudadanos en Polonia? Con juegos de niños, nos dice; con instituciones "que conforman hábitos tan queridos y afectos indestructibles" (Rousseau, 1770-1771: Cap. I). La respuesta no parece haber satisfecho las expectativas creadas con la pregunta, como se ve. Mas el ginebrino pronto echa mano del aludido espíritu de los legisladores antiguos, y aquí ya sí: los "hábitos particulares" y las "ceremonias religiosas" que establecieron "eran siempre exclusivas y nacionales", esto es, polacas en Polonia. Y ahora, los "juegos", en los que los ciudadanos pasaban varias horas reunidos, que despertaban su "orgullo y autoestima", son juegos polacos; los "espectáculos", con los que recordaban "la historia de sus ancestros" y "movían sus corazones, los inflamaban de viva emulación y generaban en ellos sólidos vínculos afectivos”, tienen a "la patria" en su centro.

Descubierta la clave, los esfuerzos se concentrarán en realizarla. $\mathrm{Al}$ respecto se proveen medidas de urgencia, a completar con la más pausada, pero incesante y universal, de la educación. La reciente experiencia de la guerra ha dejado a Polonia debilitada y frágil. Necesita "consistencia", dice Rousseau, y para ello nada mejor que empezar por republicanizar los corazones polacos instilando "el alma de los confederados en toda la nación". Es el modo más seguro de aislarlos de esa corriente europea que impide a los demás pueblos ser ellos mismos, uniformes y corruptos como se han vuelto al sucumbir ante los hechizos del lujo y el oro, convertidos en la principal razón 
de ser de sus vidas. Es urgente en cambio para los polacos nacionalizar su alma mediante nuevos valores, recrear el carácter nacional mediante "instituciones nacionales", fuente de su virtud ciudadana y de su patriotismo, y foco último de resistencia contra los deseos de conquista presentes en la voluntad de otros pueblos. El patriotismo se reivindica así como instrumento primero de nacionalización, y la historia inmediata como fuente próxima del patriotismo; de ahí, por ejemplo, que Rousseau abogue por erigir un monumento en memoria de la Confederación del Bar por su gesta heroica de conservar libre la patria, que es el modo más certero de perpetuar su memoria en el corazón de los polacos.

Con la educación, el paroxismo nacionalista alcanza su clímax. No hay un solo Emilio en Polonia, alguien que deba embeberse en su día de lecturas de clásicos, leer el Robinson Crusoe exclusivamente hasta los 15 años, o bien conocer a los pueblos del entorno viajando. El polaco, por siempre encerrado en la dorada jaula de sus fronteras, cuando aprenda a leer deberá leer "las cosas de su país"; a los 10 años deberá conocer "todos sus productos"; a los 15, "toda su historia"; a los 16, "todas sus leyes", etcétera. Lógica consecuencia de un objetivo preconcebido: "Es la educación la que debe dar a las almas la fuerza nacional, así como dirigir de tal manera sus opiniones y sus gustos que lleguen a ser patriotas por inclinación, por pasión, por necesidad. Al abrir los ojos, un niño debe ver la patria, y hasta la muerte no debe ver otra cosa. Todo auténtico republicano ha mamado con la leche de su madre el amor a su patria, es decir: de las leyes y de la libertad. Este amor constituye su entera existencia; no ve más que la patria, no vive más que para ella. Apenas está solo no es nada; apenas deja de tener a su patria, ya no es: y si no está muerto está peor". Porque: "Sólo a los hombres libres pertenece la educación nacional". ${ }^{11}$

Difícil será añadir más contundencia a la disolución del individuo en la comunidad, al rechazo al averno de su vida privada, a la adquisición de personalidad moral, la que la Voluntad General otorgaba a los miembros del Estado contractualmente establecido, en y para el todo, a la adquisición de sentido en el fondo compuesto de sentimientos, fines y opiniones comunes. El mundo se ha vola-

Todas las citas proceden de las Consideraciones sobre el gobierno de Polonia y su proyecto de reforma, y se hallan esparcidas entre los capítulos I/IV. 
tilizado; Polonia es un astro que flota en su propio espacio cósmico, auto-propulsado por su sola energía nacional, y sus patriotas son el único vestigio de vida humana sobre la tierra. Y a esa pérdida de toda materia prima de la voluntad, de la conciencia y la capacidad de decisión individual se le denomina, y sin ironía añadida, libertad.

Así pues, la educación terminará por cerrar la cuadratura del círculo político insuflando en Polonia el espíritu de las antiguas instituciones. La historia es fuente de identidad; los símbolos, que la refuerzan, se elevan a valores; los valores se acomodan a la ley; la ley es la norma básica de convivencia, de destino, que el patriota polaco lee en su corazón (el mismo ya uniforme corazón de todos); el patriota, antes ciudadano, se reconoce en los demás, que, aunados, conforman una nación; y la nación, un planeta solitario y narcisista en un universo de Estados interrelacionados, solo se mira en las aguas estancas de su historia, sus leyes y sus costumbres para reproducirse diferenciada. El nacionalismo de Rousseau, creemos, queda suficientemente compendiado ahí.

¿Cómo intervienen las consideraciones nacionalistas en la política anterior? De dos maneras al menos; la primera consiste en proporcionar un contenido material al conjunto de afirmaciones anti-individualistas, por no decir liberticidas sin más, referidas a la Voluntad General en El contrato social, como la que sanciona al soberano como el deber-ser o la rectitud inmanente de sus decisiones; la que atribuye al Estado los derechos y a los individuos las obligaciones; la que proclama la existencia de una voluntad general constante en cada sujeto singular, lista para volver a la liza apenas el interés particular egoísta se lo permita, etcétera, etcétera. Afirmaciones estas en las que se han llegado a asentar "los fundamentos filosóficos de la idea francesa de nación" (Greenfeld, 2005: 238). La segunda estriba en arrebatar, en un único golpe, a la política y a la democracia su sujeto, es decir, el pueblo de libres e iguales, y en la configuración consiguiente de un monstruo lógicamente contradictorio y políticamente totalitario, el "carácter nacional" -preclaro antecedente del futuro espíritu del pueblo-, con el que se actualizaría en la vida real la potencia de la misma índole contenida en la Voluntad General; un monstruo que, de concretarse, aniquilaría todo rastro de individualidad en el sujeto, de libertad en la voluntad y de autonomía en la razón. En cambio, ninguno de los demás pasos en falso de la nueva democracia roussoniana, la de su versión polaca -la 
Dieta, cual Voluntad General polaca, situada por encima de la ley; el censitarismo en la representación; el mandato imperativo que la define; la división social por estamentos y las jerarquías políticas derivadas de ella; la moralización extrema de la carrera política; o incluso la recién citada alienación de la soberanía del cuerpo de la nación, entre otros- pueden achacarse al nacionalismo, por mucho que guarden relación con él. Son las quiebras democráticas de una teoría basada una y otra vez en una visión dogmática y rígida de la naturaleza humana, con su perenne desconfianza en la razón, con su incredulidad en el pueblo como genuino sujeto democrático y que siempre antepuso lo moral a lo político en su concepción de la libertad, restringiendo por tanto su función, su valor y su alcance en la sociedad (Villaverde, 2014: 189).

\section{El destino del nacionalismo}

El nacionalismo es la máquina más terrible y perfecta inventada por el hombre para establecer vínculos solidarios y duraderos en un territorio determinado, y el hecho de ser una sustancia en gran medida etérea, y de serlo por mezclar en su magma constitutivo creencias, sentimientos, recuerdos, memoria, olvido, silencios manipulados, intereses, racionalidad instrumental y futuro, entre otros materiales, explica ciertamente una parte importante de la fascinación que ejerce. Y aunque su objeto, la nación, contribuya igualmente al mantenimiento de su indeterminación, sin embargo proporciona a sus miembros, los patriotas, un mundo de sentido, una fácil identidad, un sentimiento de pertenencia y la vitola de ser alguien en el interior de un proyecto común. Factores estos que proporcionan seguridad, latente cuando las sociedades pasan por periodos más o menos brillantes y cabalmente explícitos en las fases más oscuras. Por ello su virulencia inmanente resplandece en todo su fulgor en los momentos de crisis, cuando más se requiere la presencia activa y visible del enemigo de turno al que culpar del mal, y con mayor intensidad se perciben los hilos que la conjura, interna o externa, teje por envidia o resentimiento contra la inocencia propia; y de ahí el fracaso en todos los intentos de expulsarlos de la arena política. El placebo funciona con la eficacia de una vacuna gracias a los milagros que las correrías de las creencias inventan de continuo en la mente alerta del patriota. 
Por otra parte, y en el terreno intelectual, el nacionalismo goza de una propiedad diferencial frente a otros discursos o prácticas, a saber: que contribuye a constituir a la divinidad a la cual profetiza, esto es, a la Nación; lo hacía ya cuando todavía eran mayoritarios quienes creían, incluso entre los propios teóricos nacionalistas, en una nación primordial (Linz, 2008: 394, 404) que generaría en su propio seno una identidad y unos intereses prepolíticos de los que los líderes nacionalistas tomarían conciencia y contribuirían a expresar mediante la creación de un movimiento nacionalista que rematara todo ese orden de creencias, sentimientos, ideas, intereses y prácticas mediante la creación de un Estado propio (nacionalismo étnico). Y lo hace hoy aún más, cuando la nación ha pasado a concebirse como un proceso histórico y por ende contingente e inacabado, en el que el nacionalismo, en competencia con otras fuerzas políticas, deviene factor constitutivo de la realidad nacional que contribuye principalmente a modelar; y cuando ya no precisa del héroe del anterior destino: la fundación de un Estado propio (nacionalismo cívico). Por todo ello, y porque la nación de donde nace y a la que funda es un ser vivo, dotado de suma "eficacia movilizadora", ni la política, y ni siquiera la democracia, pueden considerarlo como algo ajeno a ellas (Linz, 2008). Facilita la tarea el hecho de que, en el mundo real, las dos concepciones señaladas del nacionalismo ${ }^{12}$ no funcionan por separado, sino que siempre habrá elementos característicos de la una en la otra: como la ciudadanía, propia del nacionalismo cívico, en el étnico, o la cultura, propia del étnico, en el cívico.

Ciertamente, si el concepto típico-ideal de nacionalismo étnico encarnara en una comunidad estatal, la posibilidad de que la política vea menguado su ámbito y la democracia desaparecido el suyo es total. Si algo hemos aprendido de las lecciones de Maquiavelo y Rousseau -cuyas teorías, en especial la del primero, pese a encuadrarse en un marco étnico, son en realidad protonacionalistas-, ha sido precisamente eso. Fue en Platón donde por vez primera supimos con claridad que si la política se reduce a mera técnica, su tendencia

12 Que no se corresponde con la conocida división de John Plamenatz (1973) entre, digámoslo exagerando las tintas, un nacionalismo 'europeo' con predominio teutón y el nacionalismo de los países africanos; el cual, por cierto, cuando mezcla etnicidad y colonialismo amplía con pasmosa facilidad la rica fenomenología del terror (véanse a título de ejemplo algunos de los casos citados por Josep Fontana [2011] en el cap. VI de su monumental Por el bien del Imperio. Una historia del mundo desde 1945). 
a desaparecer se dispara como por ensalmo. Y es su legado, el platonismo subrepticio que recorre gran parte del pensamiento político occidental, el que le hace resurgir en cada ocasión propicia.

En ambos pensadores hallamos ya elementos que conformarán después la guardia pretoriana conceptual del nacionalismo étnico, como el pueblo homogéneo, dotado de un pasado común y dueño de un territorio determinado; su voluntad de autogobierno en un Estado independiente ${ }^{13} \mathrm{o}$ la decidida instrumentalización del mismo a favor de su población o su cultura. Pero en sus planteamientos ello es así porque la población es sustancialmente homogénea, como la cultura, y la independencia del Estado (nacional) es la garantía exclusiva de que ambas sobrevivan en un medio violento. No se plantean ahí las divisiones étnicas y culturales de nuestra época presentes en las sociedades más desarrolladas, y por lo tanto nuestros problemas son unos felices desconocidos allí: la humanidad no se fractura sin más en dos mitades desiguales y enemigas, la nacional y la extranjera; la independencia, base del autogobierno, le preexiste, y no debe por tanto ser violentamente conquistada; y no hay un otros intraestatal contra los que arrojar las armas de la cultura, la lengua y hasta los intereses. Como resumiría Ramón Máiz, no hay una "construcción de la 'otredad' como parte sustancial de la 'mismidad"' (2008: 155). Ni siquiera a nivel teórico los planteamientos de ambos, según hemos constatado, contienen la radicalidad de un Herder o un Fichte, ${ }^{14} \mathrm{O}$ de un Renan, al que la historia ha tratado demasiado benévolamente o, en cualquier caso, de un modo inadecuado a sus intenciones, pues tenía más de romántico que de ilustrado y, desde luego, más de nacionalista étnico que de cívico. ${ }^{15}$

Ahora bien, crear de la nada histórica, es decir, de una historia en parte falsa y con deducciones en gran medida improcedentes, una nacionalidad que por sí misma no solo une, sino que también aúna, no es inocente; asesinar con ella los tumulti, vale decir, el conflicto, no solo no es tampoco inocente, sino que constituye una temeridad, porque con ellos se ha extirpado de la sociedad la fuente

13 Guiado por su “"príncipe azul' nacionalista”, naturalmente, como exclamó, con ilustrada ironía, Ernest Gellner (1988: 69).

14 En quienes, como dijo John Dunn, "el nacionalismo se convirtió en una ideología explícita del particularismo cultural, una esforzada defensa de las tradiciones teutonas frente al frágil refinamiento del cosmopolitismo galo [...]" (1993: 75).

15 Zeev Sternhell sí lo ha visto bien, según pone de relieve ya en las páginas iniciales de su voluminoso Les anti-Lumières (2006). 
de la libertad; privar a la virtù del suelo donde germinar, es decir, a la política de su condición de arte, tampoco es inocente; crear de la nada histórico-jurídica un monstruo moral con el que, también, aunar a la población, es reproducir con mayor violencia, la propia del totalitarismo, el crimen anterior; privar a los individuos de vida espiritual fuera de la masa es un crimen; transformar así la igualdad en uniformidad es un crimen, como en su día denunciaran Madison, Tocqueville o Arendt; desposeer a los sujetos de su título de soberano es un atentado deletéreo contra la cordura política que ninguna República y ninguna Democracia toleran sin destruirse. No puede serlo porque, antes o después, el infierno del totalitarismo o cualquier otra forma más púdica de autoritarismo nos saltan al paso. Y todas esas criaturas deformes sí estaban ya presentes en las teorías protonacionalistas de los dos pensadores estudiados; si al fin la historia, gracias al nacionalismo étnico, convirtió las amenazas en peligros reales, y si dio a los monstruos por doquier carnaza en la que saciar su saña, lo menos que cabe decirse de sus fautores es que no anduvieran advertidos: las creencias de Maquiavelo y Rousseau albergaban en su seno un retazo de futuro; de lo que este, cuando juega con fuego, siempre puede llegar a ser. Poco debería haber contado al respecto que el primero narrase su visión luego de convencernos de su concepción realista del hombre y del poder, y el segundo encastrase su nacionalismo sobre un molde racionalista, que por definición es siempre un molde universal.

¿Cómo recuperar entonces el nacionalismo para la política y la democracia? Desde luego, desechando dos de las tres corrientes nacionalistas modernas, la organicista y la culturalista, a causa de la prevalencia de la etnicidad en el concepto de nación que cada una presupone, bien que la naturaleza de la primera sea incomparablemente más rígida, dogmática y determinista que la de la segunda: en esta, en efecto, el componente biologista de la raza o el esencialista del espíritu del pueblo, entre otros, palpitantes en la primera, han desaparecido o han atenuado en extremo su ruido. Nos queda tan solo en pie el nacionalismo pluralista para saldar exitosamente la ardua empresa.

En este punto la historia y la experiencia unen sus fuerzas con el objeto de insuflarle cierta esperanza; en primer lugar, el cambio en el sistema de creencias políticas y en la correlación fáctica de fuerzas que desplazó al rey del trono y coronó al pueblo soberano, nivelando 
en una común igualdad jurídica la antigua jerarquía existente entre sus estratos, constituye el núcleo tanto de la idea nacional moderna como de la democracia, que, como recuerda Greenfeld, "nació con el sentimiento nacional"; lo que le lleva a concluir -rescatando una verdad del trasfondo del tiempo hoy paradójica por olvidada- que "la democracia apareció en el mundo a través del nacionalismo, contenida en la idea de nación como una mariposa en una crisálida" (Greenfeld, 2005: 10-11). ${ }^{16}$ En segundo lugar, las sociedades multinacionales de hoy empezaron siendo básicamente Estados-Nación, una estructura compleja y tan milagrosamente real que casi parece azarosa, pues refunda la convivencia humana reuniendo en torno a un marco legal común a dos gladiadores enemigos: el nacionalismo y el liberalismo. A tal punto que el nacionalismo liberal resultante llega a modelar el We the People de la Constitución de los Estados Unidos con la Nation Une del revolucionario francés Sieyès (Máiz, 2008: 184). Al pueblo racional de la teoría, con su molde universal, o al pueblo fragmentario y enfrentado de la experiencia, al que la economía moderna conmina con exigencias técnicas y a que las provea mediante un mismo sistema educativo general y estandarizado (Gellner, 1988: caps. 3 y 4), el nacionalismo los unifica con un relato histórico, una cultura, una lengua, unos símbolos y unos mitos comunes a los que el liberalismo sabrá dotar más tarde de una arquitectura jurídica caracterizada por un alto nivel de participación política y un racionalizado sistema de instituciones, garantías procedimentales y derechos individuales.

Ahora bien, el matrimonio pudo tener lugar gracias al divorcio entre la nación y algunas de sus damas de honor, y en la evolución de la nueva criatura perdería algunas más al tiempo que gana otras: había dejado de ser un dato para devenir un proceso, algo, pues, contingente y nunca cerrado... salvo -lo que era posible-si llegaba a desaparecer; por ende, había dejado de estar preconstituida antes del Estado para hacerse gracias en buena medida al concurso de éste, con lo cual la política se redimía de ser el mero eco vacío de su voz: dejaba de ser una, armónica y homogénea, para ser sustancialmente heterogénea y conflictiva, albergando además en el mismo

\footnotetext{
16 Una opinión no muy halagüeña del cambio de legitimidad puede leerse en Guy Hermet (1999: 39-40). Por otra parte, una magnífica reconstrucción intelectual del proceso señalado la puede hallar el lector en el cap. I del libro de Shlomo Sand L'invenzione del popolo ebraico (2010: 49-105), publicado originalmente en hebreo, en 2008.
} 
seno jurídico a diversas naciones rivales entre sí, con frecuencia una claramente mayoritaria respecto de las demás. ¿Es posible entonces la democracia plurinacional, o bien se recreará la endémica alternativa entre asimilación o ciudadanía de segunda?

Ese era el esperanzador legado del nacionalismo liberal, toda vez que en su denuncia del silencio nacionalista propio del liberalismo clásico planteaba sus demandas en el idioma de los derechos y de la libertad. Ni nación primordial ni identidad preestablecida; ni entidad prepolítica ahistórica ni demandante de un Estado propio. Ahora bien, cuando la crítica penetra en el búnker del dogma lo hace para ventilar el entero edificio, no una única estancia. Y la historización de la nación no se iba a detener en la reivindicación de una historia abierta para ella, en la denuncia de su manipulación -falsificándola o inventándola- o en expulsar perentoriamente a algunos de sus ídolos más venerados, como la raza o el espíritu del pueblo, de sus respectivos altares. La cultura en persona iba a pasar bajo su criba, bien que esa nueva tarea rebasaba las lindes del citado nacionalismo (Máiz, 2008: 188-198) y fue el desafío al que iba a hacer frente el nacionalismo (democrático) pluralista.

Historizar la historia despojándola de su carácter de mito ilusoriamente sacro para devolverla al flujo del tiempo, y con ello, a todo su contenido -esto es, a todo, porque todo en el ser humano es histórico-, hace que las culturas y las naciones -a las que en concurrencia con otros factores contribuía a calificar- adquieran un carácter abierto y plural, mutable y conflictivo, fluido y poroso, en claro contraste con la rígida y esencial criatura anterior. Estas culturas rebasan las fronteras de las actuales naciones con similar facilidad a como el nacionalismo organicista las superponía a las anteriores; y si bien influyen en los individuos a los que recrean, en absoluto los dotan de ninguna identidad perenne. Más aún, los individuos, en este nuevo mundo de ideas tan en sintonía con la realidad que de hecho conforman, recobran su autonomía, su voluntad, su libertad y, con ellas, su capacidad de dotar de sentido a sus propias vidas, en un proceso asimismo abierto, contradictorio y conflictivo, tanto en sus relaciones con los demás como en las que mantienen con su propio pasado, al que pueden variar mediante opciones nuevas deliberadamente opuestas o en tensión con la biografía vivida hasta el presente, en un acto de libre, saludable y audaz incoherencia. Una de las consecuencias más palmarias y paradójicas es que cada 
sujeto puede sin más asimilar voluntariamente como propios cuantos rasgos culturales repute valiosos entre los que flotan a su alrededor provenientes de las culturas que conviven con la suya, vale decir: en los Estados multiculturales los individuos serán probables exponentes de identidades plurinacionales.

Hemos aludido en este punto a las 'culturas' cuando parecían disueltas en la atmósfera del Estado democrático plurinacional ${ }^{17}$ porque, a pesar de la pérdida de todo elemento monista y esencial de raíz comunitaria, la mayoría de los individuos aún inscriben su conducta personal en una esfera de referencias comunes y de sentimientos compartidos con otros, en la que los vínculos de identidad y pertenencia se han atenuado sin disolverse; y porque previsiblemente la condición voluntaria de las culturas, en lugar de la adscriptiva, así como la yuxtaposición entre agrupaciones comunitarias vistas como indiferentes o, peor aún, como distantes, rivales o hasta enemigas, apenas suene la hora del conflicto les hará no solo pervivir sino también refluir hacia tentaciones holistas y étnicas que celosamente se esconden en su seno.

Son esos aparentes residuos de colectivismo el único territorio que el nacionalismo puede compartir con la democracia, y en ese ámbito la sola ley, y única muralla contra la doble divisa multiculturalista del 'todo vale' y 'todo vale igual', es la de los derechos humanos, la tolerancia y ese conjunto de reglas comunes que garantizan un trato equitativo a las diversas partes, pero que deben también forzar a contener a cuantos elementos autoritarios y liberticidas -ya sea que provengan del organicismo nacionalista o religioso, o bien del fundamentalismo economicista- en la otra orilla de la legalidad. Ley ésa que fuerza a la pluralidad de culturas que conviven bajo una única jurisdicción y en un mismo territorio al diálogo, la mutua tolerancia y la interrelación inclusiva, en un marco en el que, sin apelar dogmáticamente a derechos primordiales más o menos enraizados en creencias trascendentes o fundamentalistas, cada una pueda defender sus intereses de acuerdo con las nuevas ideas de construcción, proceso, indeterminación y apertura que acompañan al renovado

\footnotetext{
17 Que según algunos de sus conspicuos defensores debe ser federal, como señala el propio Máiz, prolongando los pasos de Linz (2008: cap. 10), con docta e incisiva rotundidad en el último capítulo de su obra varias veces citada.
} 
concepto de nación y al conjunto de sus materiales constitutivos; un marco en el que cada una reconozca naturalmente los derechos de las demás y en el que, de este modo, constaten y asuman en tales derechos un límite racional al ejercicio de los suyos. Porque aquí, en definitiva, ya no es solo el nacionalismo el que se juega su destino, ni la política o la República, como en Maquiavelo o Rousseau a su sujeto político: en ese envite son ya la propia democracia y la cultura humanitaria las que se juegan su supervivencia 【 


\section{Referencias}

Crick, Bernard (1971). In Defence of Politics. Middlesex, UK: Penguin Books.

Dunn, John (1993). Western Political Theory in the Face of the Future. Cambridge: Cambridge University Press.

Fontana, Josep (2011). Por el bien del Imperio. Una historia del mundo desde 1945. Barcelona: Pasado y Presente.

Gellner, Ernest (1988). Naciones y nacionalismo. Madrid: Alianza Editorial. Greenfeld, Liah (2005). Nacionalismo. Cinco vías hacia la modernidad. Madrid: Centro de Estudios Políticos y Constitucionales (CEPC).

Hermet, Guy (1999). "Populismo y nacionalismo". En: Araucaria, No. 2, pp. 39-57.

Hermosa Andújar, Antonio (1988). El Proyecto y las Consideraciones: evolución e involución en el pensamiento político de Rousseau. Madrid: Tecnos. Hermosa Andújar, Antonio (2006). "Introducción: 'De Florencia a Italia: Maquiavelo, nacionalista”. En: Niccolo Maquiavelo. El príncipe (edición de Antonio Hermosa Andújar). Buenos Aires: Prometeo Libros.

Linz, Juan (2008). "Nación, Estado y lengua”. En: Obras escogidas, Vol. II. Madrid: Centro de Estudios Políticos y Constitucionales (CEPC).

Máiz, Ramón (2008). La frontera interior. El lugar de la nación en la teoría de la democracia y el federalismo. Murcia: Tres Fronteras Ediciones.

Maquiavelo, Niccolo (1987). Discursos sobre la primera década de Tito Livio. Libro III. Madrid: Alianza Editorial.

Maquiavelo, Niccolo (2006). El príncipe (edición de Antonio Hermosa Andújar). Buenos Aires: Prometeo Libros.

Plamenatz, John (1973). "Two Types of Nationalism". En: Eugene Kamenka (ed.). Nationalism, the Nature and Evolution of an Idea (pp. 23-36). Canberra: Australian National University Press.

Ritter, Gerhard (1972). "Maquiavelo y los orígenes del nacionalismo moderno". En: El problema ético del poder. Madrid: Revista de Occidente.

Rousseau, Jean-Jacques (1964). "Du Contrat social - Écrits politiques". En: Oeuvres Complètes, Libro III. París: Gallimard.

Rousseau, Jean-Jacques (2002 [1770-1771]). Considérations sur le Gouvernement de Pologne: Et sur sa réformation projetée. Chicoutimi: J.- M. Tremblay

Sand, Shlomo (2010). L'invenzione del popolo ebraico. Milano: Rizzoli.

Sternhell, Zeev (2006). Les anti-Lumières. París: Fayard. 
Villaverde, María José (2014). "Forjadores de paz: de la polis a la Ilustración”. En: Araucaria, No. 32, pp. 173-196.

Zweig, Stefan (2002). "El genio de una noche". En: Momentos estelares de la humanidad. Barcelona: Acantilado. 